\title{
Reduced Sensitivity in Monilinia fructicola to Propiconazole Following Prolonged Exposure in Peach Orchards
}

\author{
Eldon I. Zehr and Lynn A. Luszcz, Department of Plant Pathology and Physiology, William C. Olien and W. C. \\ Newall, Department of Horticulture, and Joe E. Toler, Department of Experimental Statistics, Clemson University,
} Clemson, SC 29634-0377

\begin{abstract}
Zehr, E. I., Luszcz, L. A., Olien, W. C., Newall, W. C., and Toler, J. E. 1999. Reduced sensitivity in Monilinia fructicola to propiconazole following prolonged exposure in peach orchards. Plant Dis. 83:913-916.

The baseline sensitivity of Monilinia fructicola in a peach orchard not previously exposed to demethylation-inhibiting (DMI) fungicides was determined for propiconazole, using the concentration in an agar medium required to suppress radial growth of mycelium by $50 \%\left(\mathrm{EC}_{50}\right)$. The baseline sensitivity was found to be approximately $0.03 \mu \mathrm{g} / \mathrm{ml}$. Prolonged, regular exposure of the natural population of $M$. fructicola to propiconazole in the test orchard over a 3-year period (29 total applications) resulted in a wider range of sensitivity $\left(\mathrm{EC}_{50}\right.$ of 0.02 to 2.16 $\mu \mathrm{g} / \mathrm{ml})$ among isolates than was observed in the initial population $\left(\mathrm{EC}_{50}\right.$ of 0.02 to $\left.0.15 \mu \mathrm{g} / \mathrm{ml}\right)$. Comparisons with isolates from commercial orchards where DMI fungicides were used regularly showed that sensitivities were comparable to, or less than, those of isolates from the population in the test orchard that had been exposed to propiconazole for the 3-year period. $M$. fructicola in South Carolina peach orchards might now be less sensitive to DMI fungicides than when those fungicides were first introduced for brown rot control, although effective disease control in the field has been maintained.
\end{abstract}

Demethylation-inhibiting (DMI) fungicides have become essential components in the choices available to growers to combat many plant diseases. More than 20 chemical fungicides have this mode of action (3), and many of them are used widely in crop production. As with benzimidazoles and other fungicides that have systemic activity, DMI fungicides are subject to resistance problems. Their regular use may result in the development of variants that are no longer controlled in nature, leading to reduced effectiveness or loss of disease control when they are used $(1-5,7,8)$.

DMI fungicides are widely used in South Carolina stone fruit orchards for control of brown rot caused by Monilinia fructicola. They effectively replaced the benzimidazole fungicides that were used until the early 1980s, when widespread

Corresponding author: E. I. Zehr

Current address of W. C. Olien: Blandy Experimental Farm, 400 Blandy Farm Lane, Boyce, VA 22620 .

Contribution 4483 of the South Carolina Agriculture and Forestry Research System, Clemson University.

Accepted for publication 11 June 1999.

Publication no. D-1999-0727-01R

This article is in the public domain and not copyrightable. It may be freely reprinted with customary crediting of the source. The American Phytopathological Society, 1999. resistance to the benzimidazoles led to ineffective brown rot control. Triforine replaced benomyl and thiophanate-methyl in most South Carolina peach (Prunus persica) orchards in the 1980s. More recently, propiconazole, fenbuconazole, and tebuconazole have become the leading DMIs used, and because of cost and efficacy, those fungicides are used almost exclusively for brown rot control during flowering and preharvest periods in many peach orchards in South Carolina.

Widespread use of the DMIs in peach orchards prompted us to study the potential for resistance to develop as a consequence of regular, exclusive use of propiconazole, a representative of this class of compounds. We studied changes in sensitivity of the pathogen to propiconazole in an isolated peach orchard using prolonged regular exposure over 3 years and compared the resulting changes with sensitivities of isolates from commercial orchards where DMI fungicides have been used routinely.

\section{MATERIALS AND METHODS}

Orchard site. The site chosen to determine baseline sensitivity was the Musser Farm, a new location for a fruit research center at Clemson University, located in a semirural area. No known commercial stone fruit orchards existed within a $15-\mathrm{km}$ radius, and none were known to exist at the location prior to 1987 . The orchard chosen consisted of 6-year-old peach and nectarine (P. persica var. nucipersica) trees of mixed cultivars and was approximately 1.5 ha in area. The orchard consisted of two to four trees of each cultivar or breeding selection, and because the cultivars were not arranged according to ripening sequence, almost weekly fungicide applications over the entire orchard were needed for brown rot control during the period from early May to mid-August.

DMI fungicides had not been used in the test orchard prior to 1993, and only one (triforine) had been used sparingly (one or two applications per year) during the previous 2 years in other small, experimental peach orchards 0.5 to $1.0 \mathrm{~km}$ distant

Sample collection. Sample collection for baseline assays began after bloom in 1993. Approximately 50 infected flowers and twigs were collected at random early in May before the first propiconazole application. Not more than five infected flowers or twigs were collected from any single tree. M. fructicola was isolated from the infected tissue on water agar amended with streptomycin sulfate at $10 \mu \mathrm{g} / \mathrm{ml}$, either by transferring conidia aseptically to the agar medium or (if the fungus was not sporulating) isolating from woody tissue after surface disinfestation with $70 \%$ ethanol. After the conidia germinated, a hyphal tip from a germinating conidium was transferred aseptically to potato dextrose agar (PDA).

Sensitivity to propiconazole. Sensitivity was determined by incorporating technical grade propiconazole or formulated product (Orbit 3.6E) into autoclaved, cooled PDA at 0.0075 to $0.250 \mu \mathrm{g}$ a.i. $/ \mathrm{ml}$ (technical grade and formulated product gave the same results in preliminary trials) using increments of $0.015,0.03,0.06$, and $0.125 \mu \mathrm{g} / \mathrm{ml}$. If isolates failed to grow at $0.015 \mu \mathrm{g} / \mathrm{ml}$, additional concentrations of $0.0075 \mu \mathrm{g} / \mathrm{ml}$ were tested or, for isolates that appeared to be less sensitive, a concentration of $0.250 \mu \mathrm{g} / \mathrm{ml}$ was used. Each batch of medium was prepared immediately prior to the beginning of each experiment. A 5-mm plug of mycelium of $M$. fructicola on PDA was placed on the medium in the center of each petri dish, cultures were incubated at $25^{\circ} \mathrm{C}$ in darkness, and colony diameters were measured after 5 days. Each concentration of propiconazole was replicated three times, and at least three concentrations of propiconazole were tested relative to the control (nonamended PDA). The $\mathrm{EC}_{50}$ concentration (dose re- 
quired to reduce colony diameters $50 \%$ relative to the control) was determined by converting the measurements to natural logarithms and preparing a regression line for each isolate. For less-sensitive isolates $\left(\mathrm{EC}_{50}\right.$ values > 0.250), $\mathrm{EC}_{50}$ values were determined by extrapolation of the converted measurements.

Response to applications of propiconazole. During the 1993 to 1995 growing seasons, changes in sensitivity to propiconazole in the test orchard were monitored using the procedures described above. Propiconazole (Orbit 3.6E) was applied at the label recommended rate of $292 \mathrm{ml} / \mathrm{ha}$ on $27 \mathrm{May}, 10,17$, and 24 June, 2, 8, 16, and 23 July, and 9, 13, 19, and 26 August 1993 (12 applications total). Applications in 1994 were on 19 and 26 May, 2, 14, 20, and 30 June, 8, 15, and 28 July, and 8 and 17 August (11 applications). In 1995, propiconazole was applied on 22 May, 5, 13 , and 26 June, and 10 and 28 July (6 applications). Triforine (Funginex 1,752 $\mathrm{ml} / \mathrm{ha}$ ) was used once during bloom in March 1993 and once in March 1994. Samples of blighted blossoms were collected at random before the first propiconazole application each year, and up to $50 \mathrm{M}$. fructicola-infected fruits were collected once each month (4 months in 1993 and 1994 and 3 months in 1995) during the time of propiconazole application. (The number depended on availability of infected blossoms or ripening fruit in the orchard.) Single-spore cultures were prepared from the infected fruits or flowers as described previously, and the $\mathrm{EC}_{50}$ value was determined for each isolate as described previously.

Sensitivity of isolates from commercial orchards. Isolates of M. fructicola collected at random from commercial peach orchards where DMI fungicides had been used in blossom and preharvest sprays for brown rot control for 3 to 10 years. DMI fungicides had continued to provide satisfactory brown rot control up were collected from decaying peach fruit

to the time that the isolates were collected. In 1995, the isolates collected were primarily from the Ridge (west central) part of the state, whereas those collected in 1996 were predominantly from the Piedmont (extreme north) part of South Carolina. Isolates collected in 1995 represented 11 commercial growers, whereas the 1996 isolates were from seven commercial growers. Single-spore isolates were prepared, and the $\mathrm{EC}_{50}$ values were determined as described previously.

In addition, a small commercial orchard in Anderson County, South Carolina, was chosen for more detailed sampling in 1995 and 1996. This 1.5-ha orchard consisted of peach and nectarine cultivars that ripened in sequence from mid-June to mid-August. DMI fungicides (triforine and propiconazole) were used in this orchard in the preharvest sprays from 1984 to 1996, and occasionally (propiconazole, fenbuconazole, or myclobutanil) for blossom blight control when needed. The dicarboximide iprodione was substituted for DMIs in some years. A total of 27 DMI fungicide applications and 11 dicarboximide applications were made in this orchard from 1989 through 1995. Single-spore isolates were prepared, and the $\mathrm{EC}_{50}$ values were calculated.

Statistical analyses. A two-sample median test (6) was used to examine results. $\mathrm{EC}_{50}$ values were subjected to chi-square analyses to evaluate changes in sensitivity in the test site and in the commercial orchards from year to year.

\section{RESULTS}

Weather and crop conditions. Rainfall during the 1993 growing season was comparatively light $(131 \mathrm{~mm}$ from 15 May to 15 August). In contrast, rainfall was plentiful in 1994 and 1995 (485 and $286 \mathrm{~mm}$, respectively). Rainfall amounts affected the number of fruits infected with $M$. fructicola at the Musser Farm test site. Numbers each monthly sampling period were low in 1993, but larger in 1994 and 1995.

Table 1. Range of sensitivity of isolates of Monilinia fructicola to propiconazole before and after repeated propiconazole applications in South Carolina peach orchards ${ }^{\mathrm{a}}$

\begin{tabular}{lccccc}
\hline & & \multicolumn{3}{c}{$\mathbf{E C}_{\mathbf{5 0}}(\boldsymbol{\mu g} / \mathbf{m l})^{\mathbf{b}}$} & \\
\cline { 3 - 5 } Source of isolates & Isolates (no.) & Range & Median & Mean & Mean $\boldsymbol{r}^{\mathbf{2}}$ \\
\hline Musser Farm, initialc & 44 & $0.02-0.15$ & 0.03 & 0.04 & 92.0 \\
Musser Farm, 1993 & 52 & $0.01-0.19$ & 0.03 & 0.04 & 91.4 \\
Musser Farm, 1994 & 89 & $0.01-0.25$ & 0.04 & 0.05 & 90.3 \\
Musser Farm, 1995 & 51 & $0.02-2.16$ & 0.06 & 0.18 & 82.1 \\
Anderson County, 1995 & 58 & $0.01-2.62$ & 0.02 & 0.12 & 84.4 \\
Anderson County, 1996 & 61 & $0.01-2.00$ & 0.04 & 0.12 & 89.5 \\
Commercial peach, 1995 & 47 & $0.01-1.82$ & 0.085 & 0.15 & 86.2 \\
Commercial peach, 1996 & 29 & $0.02-1.09$ & 0.04 & 0.13 & 84.2 \\
\hline
\end{tabular}

${ }^{a}$ Musser Farm site received no demethylation-inhibiting (DMI) fungicides prior to 1993 but was sprayed 29 times with propiconazole from 1993 to 1995. Anderson County site received 27 DMI fungicide applications interspersed with 11 dicarboximide applications from 1989 to 1995. In other commercial orchards, DMI fungicides were the principal fungicides used.

${ }^{\mathrm{b}}$ Concentration of propiconazole in potato dextrose agar required to suppress radial growth of mycelium $50 \%$.

${ }^{\mathrm{c}}$ Isolates collected before the first application of propiconazole.
The fruit crop was sufficient for experimental purposes each year except 1996, when late freezes decimated the fruit crop in the commercial orchards sampled. Fruit samples collected in 1995 from commercial orchards had been exposed to DMI fungicides during 1995. Those collected in 1996 were from commercial orchards that were not sprayed because the crop was insufficient to justify fungicide sprays, except at the Anderson County site, where two or three DMI fungicide (fenbuconazole) sprays were applied.

Baseline sensitivity. The baseline sensitivity of $M$. fructicola, according to the $\mathrm{EC}_{50}$ value for mycelial suppression, was approximately $0.03 \mu \mathrm{g} / \mathrm{ml}$, determined from 44 isolates collected before the first application of propiconazole (Table 1). Sensitivity deviated from this level only slightly among the 44 isolates (range of 0.02 to $0.15 \mu \mathrm{g} / \mathrm{ml}$ ) (Table 1 ).

Changes in sensitivity to propiconazole. Sensitivity changed little, if at all, during the 1993 growing season $\left(\mathrm{EC}_{50}\right.$ range of 0.01 to $0.19 \mu \mathrm{g} / \mathrm{ml}$ ). Chi-square comparisons showed no significant difference between the means of isolates collected after spraying in 1993 and the mean sensitivity of the initial population (data not shown). Likewise, the mean sensitivity of isolates collected in 1994 did not differ significantly from that of isolates tested in 1993 (Fig. 1 and Table 2). However, in 1995, there appeared to be a shift toward reduced sensitivity to propiconazole in the Musser Farm orchard (Fig. 1) relative to the level of sensitivity found in 1993 and 1994. The median and mean levels of sensitivity increased in 1995 (Table 1), as did the percentage of isolates sensitive to propiconazole only at higher concentrations $\left(\mathrm{EC}_{50}\right.$ $\geq 0.1 \mu \mathrm{g} / \mathrm{ml}$, Fig. 1 and Table 2).

Sensitivity of isolates from commercial orchards. Isolates of $M$. fructicola collected in 1995 and 1996 from commercial peach orchards where DMI fungicides were used regularly were less sensitive to propiconazole, on average, than isolates from the Musser Farm in 1993 (Tables 1 and 2, Fig. 2). Moreover, isolates from commercial orchards were less sensitive on average than those collected at the Musser Farm orchard in 1995, where 29 sprays of propiconazole had been applied over a 3year period. Sensitivity of isolates from the small Anderson County orchard, where sprays of DMI fungicides were interspersed with iprodione, a dicarboximide fungicide, was intermediate between the baseline $\mathrm{EC}_{50}$ value and that of other commercial orchards in 1995 , but did not differ significantly from other commercial orchards in 1996 (Table 2).

\section{DISCUSSION}

The baseline sensitivity to propiconazole for $50 \%$ suppression of mycelial growth $\left(\mathrm{EC}_{50}\right)$ of $M$. fructicola is approximately $0.03 \mu \mathrm{g} / \mathrm{ml}$ for South Carolina isolates. The 
data supporting this conclusion are based on a single isolated location; however, DMI fungicides are so widely used for brown rot control in South Carolina that peach orchards not previously exposed to these fungicides are difficult to locate. Supporting this value as a baseline are data from the other orchards that show highly sensitive isolates to have sensitivities similar to those from the Musser Farm site. However, this level differs from that reported by Wilcox and Burr (9), who found the baseline in isolates they tested to be $0.009 \mu \mathrm{g} / \mathrm{ml}$.

The average sensitivity of isolates appeared to decrease in response to multiple applications of propiconazole at the Musser Farm test site in 1993 to 1995, but a nonsprayed site nearby was not available for comparison. The change from 1993 to 1995 did not result from reduced sensitivity in all isolates, but from an increased frequency of isolates that were less sensitive. The range of sensitivity among isolates from the site also increased (Table 1).

Isolates from commercial orchards included an even larger percentage of isolates that were less sensitive to propiconazole than at the Musser Farm site in 1995, where 29 applications of propiconazole were made over a 3-year period. This finding indicates that regular use of DMI fungicides in South Carolina peach orchards might have already resulted in less sensitivity to DMIs in the general population of $M$. fructicola. In the Anderson County orchard where iprodione was used frequently instead of a DMI fungicide, isolates in 1995 generally were more sensitive to propiconazole than those from other commercial orchards. In 1996, the sensitivity of the Anderson County versus other orchards was not significantly different, but the Anderson County isolates in 1996 originated from fruits that were sprayed with a DMI fungicide, whereas fruits from other orchards had not been sprayed because crop failure had resulted from spring freezes. Differences in fungicide application practices in these orchards in 1996 might have influenced the sensitivity of the isolates collected.

As of 1998, we have not encountered failures to control brown rot in commercial peach orchards in South Carolina because of resistance to DMI fungicides. The apparent increased frequency of less sensitive strains in peach orchards found in this study has not noticeably affected brown rot control up to this point. Substitution of DMI fungicides with others of a different mode of action (iprodione in the Anderson County orchard) appeared to lessen the frequency of less sensitive strains relative to the other commercial orchards examined.

We did not evaluate the fitness or persistence of the less sensitive isolates of $M$. fructicola found in this study. Reduced sensitivity might not be a persistent trait.

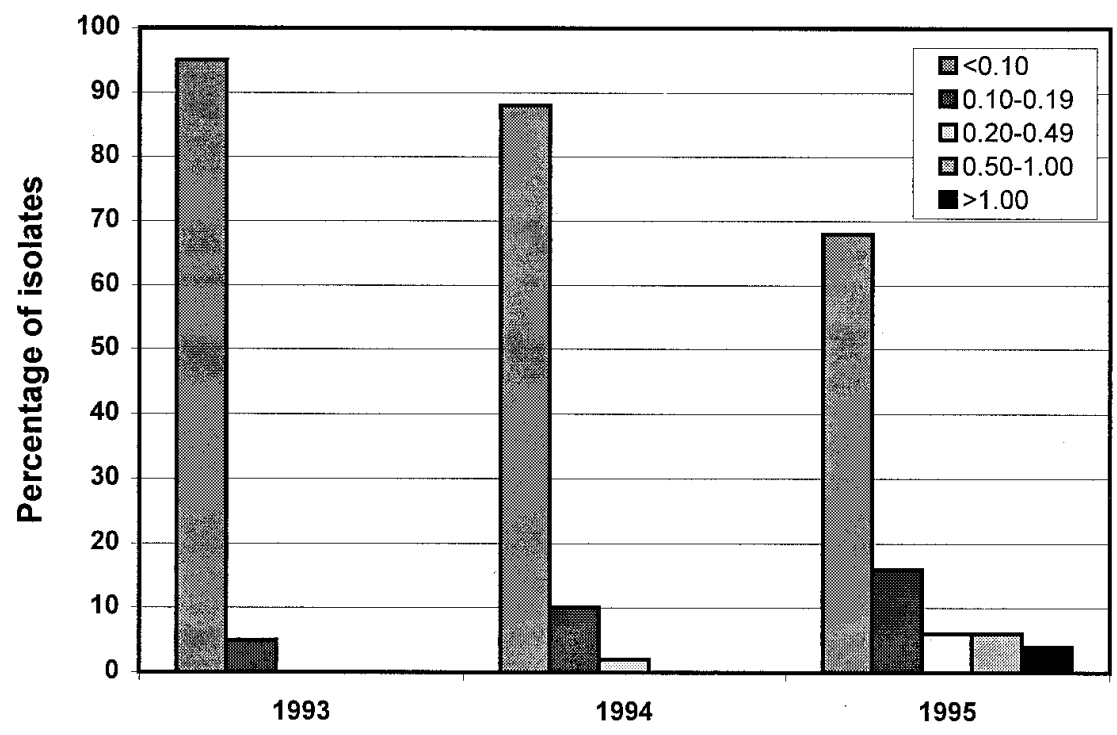

Fig. 1. Changes in sensitivity of Monilinia fructicola to propiconazole in response to frequent applications of the fungicide in an experimental orchard (Musser Farm) from 1993 to 1995. Data represent the distribution of $\mathrm{EC}_{50}$ values (concentration required to reduce mycelial growth by $50 \%$ ) among the isolates.

Table 2. Comparisons of sensitivity of Monilinia fructicola in test orchards, 1993 to 1996, using two-sample median tests ${ }^{\mathrm{a}}$

\begin{tabular}{lc}
\hline Comparison & Chi-square value \\
\hline Musser Farm, 1993 vs. 1994 & 0.2459 \\
Musser Farm, 1993 vs. 1995 & $12.9141^{\mathrm{b}}$ \\
Musser Farm, 1994 vs. 1995 & $5.9763^{\mathrm{b}}$ \\
Anderson County, 1995 vs. 1996 & $14.2472^{\mathrm{b}}$ \\
Anderson County, 1995 vs. other commercial, 1995 & $31.1742^{\mathrm{b}}$ \\
Anderson County, 1996 vs. other commercial, 1996 & 0.0935 \\
Commercial orchards, 1995 vs. 1996 & 2.3433 \\
Commercial orchards, 1995 vs. Musser Farm, 1995 & $3.9499^{\mathrm{b}}$ \\
Anderson County, 1995 vs. Musser Farm, 1995 & $13.7475^{\mathrm{b}}$ \\
\hline
\end{tabular}

a Comparisons of median values from orchard sites listed in Table 1.

b Median values are different at $P=0.05$ (critical chi-square value $=3.841$ ).

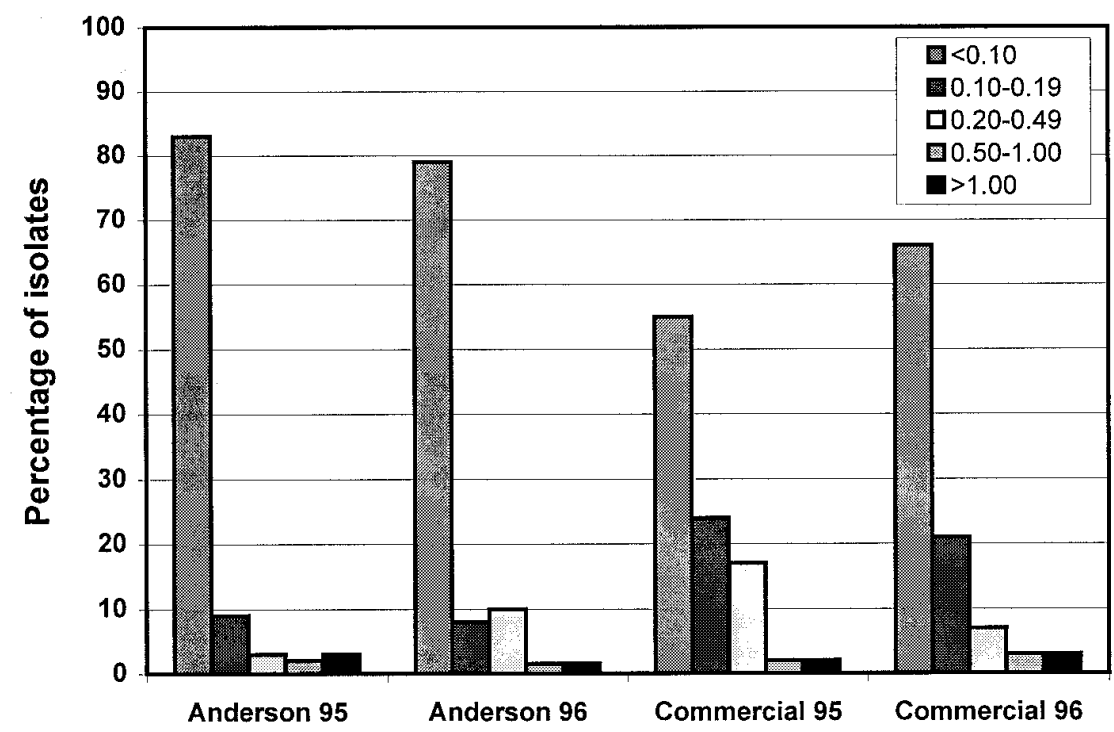

Fig. 2. Relative sensitivity of isolates of Monilinia fructicola to propiconazole collected from commercial peach or nectarine orchards in 1995 and 1996. In the Anderson County orchard, iprodione was substituted for propiconazole some years for resistance management, whereas in the other commercial orchards, a demethylation-inhibiting fungicide was used regularly for brown rot suppression. 
We have observed (unpublished data) that when less sensitive strains were stored at $5^{\circ} \mathrm{C}$ on agar slants for 6 months or more, their sensitivity often reverted to levels near the baseline of $0.03 \mu \mathrm{g} / \mathrm{ml}$. However, lack of fungicide applications in commercial orchards as a result of crop loss in 1996 might have resulted in more frequent infections by, or less suppression of, the more sensitive strains instead of reversion to greater sensitivity in less sensitive strains. Each of the comparisons made indicates that regular use of DMI fungicides increases the frequency of less sensitive strains of $M$. fructicola. Stability of reduced sensitivity in individual strains is a subject for additional research. Regardless, management of resistance to DMI fungicides should include intelligent use of fungicides having other modes of action, such as alternating or substituting chemicals having different modes of activity during the susceptible bloom and ripening periods.

\section{ACKNOWLEDGMENT}

We thank Steven N. Jeffers for assistance with manuscript preparation.

\section{LITERATURE CITED}

1. De Waard, M. E., Georgopoulous, S. G., Hollomon, D. W., Ishii, H., Leroux, P., Ragsdale, N. N., and Schwinn, F. J. 1993. Chemical control of plant diseases: Problems and prospects. Annu. Rev. Phytopathol. 31:403-421.

2. Golembiewski, R. C., Vargas, J. M., Jr., Jones, A. L., and Detweiler, A. R. 1995. Detection of demethylation inhibitor (DMI) resistance in Sclerotinia homoeocarpa populations. Plant Dis. 79:491-493.

3. Köller, W. 1996. Recent developments in DMI resistance. Pages 301-311 in: Modern Fungicides and Antifungal Compounds. H. Lyr, P. E. Russell, and H. D. Sisler, eds. Intercept Ltd.,
Andover, UK

4. Köller, W., Parker, D. M., and Reynolds, K. L. 1991. Baseline sensitivities of Venturia inaequalis to sterol demethylation inhibitors. Plant Dis. 75:726-728.

5. Köller, W., Wilcox, W. F., Barnard, J., Jones, A L., and Braun, P. G. 1997. Detection and quantification of resistance of Venturia inaequalis populations to sterol demethylation inhibitors. Phytopathology 87:184-190.

6. Mood, A. M. 1950. Introduction to the Theory of Statistics. McGraw-Hill, New York.

7. Smith, F. D., and Köller, W. 1990. The expression of resistance of Ustilago avenae to the sterol demethylation inhibitor triadimenol is an induced response. Phytopathology 80:584-590.

8. Sutton, T. B. 1996. Changing options for the control of deciduous fruit tree diseases. Annu. Rev. Phytopathol. 34:527-547.

9. Wilcox, W. F., and Burr, J. A. 1994. Base-line sensitivity of Monilinia fructicola to six DM fungicides. (Abstr.) Phytopathology 84:1078. 